BIOFARM

Jurnal Ilmiah Pertanian

ISSN Print: 0216-5430; ISSN Online: 2301-6442

Vol. 15, No. 2, Oktober 2019

\title{
Pengaruh Variasi Kadar Salinitas Media dan Macam Bahan Amelioran Terhadap Pertumbuhan Azolla microphylla kaulf
}

\section{Effect of Media Salinity Level Variation and Ameliorant Material on the Growth of Azolla microphylla kaulf}

\author{
Nur Rihin ${ }^{1 *}$ \\ ${ }^{1}$ Program Studi Agroteknologi, Fakultas Pertanian, Universitas Pekalongan \\ *Korespondensi Penulis: 7nurrihin@gmail.com
}

\begin{abstract}
ABSTRAK
Penelitian bertujuan mengetahaui kadar salinitas media dan macam bahan amelioran yang tepat serta interaksi antara kadar salinitas media dan macam bahan amelioran terhadap pertumbuhan Azolla microphylla Kaulf, dilaksanakan di Desa Toso Kecamatan Bandar Kabupaten Batang pada ketinggian 500 mdpl, pada Oktober 2018 sampai November 2018. Rancangan percobaan yang digunakan : Rancangan Acak Kelompok, perlakuan faktorial $4 \times 3$. Faktor pertama kadar salinitas media 4 taraf : $0 \%, 5 \%, 10 \%, 15 \%$. Faktor kedua macam bahan amelioran 3 taraf : pupuk kandang sapi, zeolit, dolomit. Variabel yang diamati : Laju pertumbuhan relatif per tanaman, panjang batang per tanaman, panjang akar per tanaman, kemunculan jumlah akar per tanaman, pertambahan biomasa berat basah per tanaman, bobot kering per tanaman, waktu penggandaan per tanaman, kepadatan per bak plastik, jumlah tanaman bertahan hidup per bak plastik, kandungan N Azolla segar per sampel, kandungan $\mathrm{N}$ kompos Azolla per sampel. Hasil penelitian menunjukkan kadar salinitas media berpengaruh sangat nyata terhadap semua variabel dengan pola pengaruh bersifat linier. Kadar salinitas media 5\% Azolla microphylla Kaulf masih toleran. Macam bahan amelioran berpengaruh sangat nyata terhadap semua variabel. Bahan amelioran terbaik adalah pupuk kandang sapi. Interaksi kadar salinitas media dan bahan amelioran berpengaruh sangat nyata terhadap semua variabel. Kombinasi terbaik kadar salinitas media $5 \%$ dan pupuk kandang sapi.
\end{abstract}

Kata Kunci : Azolla microphylla Kaulf, kadar salinitas media, macam bahan amelioran.

\begin{abstract}
The study aimed to determine the salinity of the media and the types of ameliorant materials that were appropriate and the interaction between the salinity of the media and the type of ameliorant material on the growth of Azolla microphylla Kaulf, carried out in the village of Toso, Bandar Subdistrict, Batang at an altitude of 500 md to November 2018. used: Randomized Group Design, $4 \times 3$ factorial treatment. The first factor is the 4 level media salinity level: $0 \%, 5 \%, 10 \%, 15 \%$. The second factor is the type of ameliorant 3 level: cow manure, zeolite, dolomite. Variables observed were: relative growth rate each plant, stem length each plant, root length each plant, appearance of number of roots each plant, increase in biomass wet weight each plant, dry weight each plant, doubling time each plant, density each plastic tub, number of plants surviving each plastic tub, fresh $N$ Azolla content each sample, $N$ content of Azolla compost each sample. The results showed that the salinity of the media had a very significant effect on all variables with patterns of influence that were linear. Media salinity levels 5\% Azolla microphylla Kaulf is still tolerant. Ameliorant materials have a very significant effect on all variables. The best ameliorant is cow manure. The interaction of salinity levels of media and ameliorant materials had a very significant effect on all variables. The best combination of $5 \%$ media salinity and cow manure
\end{abstract}

Keywords: Azolla microphylla Kaulf, salinity of media, kinds of ameliorant materials.

\section{PENDAHULUAN}

Azolla merupakan salah satu tumbuhan yang memiliki banyak manfaat dalam bidang pertanian organik. Tumbuhan ini umumnya dapat dijumpai di perairan tergenang, tergolong tanaman istimewa karena mampu memfiksasi N2 dari udara. Kandungan unsur hara yang terdapat dalam Azolla sp. yaitu N (1,96-5,30\%), P $(0,16-$ $1,59 \%)$, Si $(0,16-3,35 \%)$, Ca $(0,31-0,97 \%)$, Fe $(0,04-0,59 \%)$, Mg $(0,22-0,66 \%)$, Zn (26989 ppm), Mn (66-2944 ppm) (Surdina dkk.,
2016). Manfaat Azolla antara lain : sebagai pupuk organik, pakan ternak dan bahan biogas. Azolla mudah dibudidayakan dan digunakan sebagai pupuk hayati atau pupuk hijau. Azolla termasuk tumbuhan berkualitas tinggi. Sebagai green manure memiliki kandungan $\mathrm{N}$ tinggi, kandungan lignin dan polifenol rendah (Mamang dkk., 2017).

Kebutuhan Azolla sebagai pupuk organik cukup tinggi. Kebutuhan pupuk organik untuk padi sawah secara nasional 
cukup tinggi, yakni 9,8-13,4 juta ton/tahun, sedangkan produksi pupuk organik rata-rata 2 ton/tahun, sehingga produksi pupuk organik masih jauh dari kebutuhan (Irawan dkk., 2017).

Rendahnya produksi Azolla di Jawa pada kawasan Pantura disebabkan adanya intrusi air garam. Cekaman garam (salin) pada tanaman bisa mengakibatkan pertumbuhan tidak normal, daun kecil dan terbakar, pertumbuhan kerdil, buah tidak sempurna, dan hasil menurun. Kadar garam yang tinggi merupakan hasil dari pembentukan mineral-mineral garam terlarut, akumulasi garam dari irigasi yang membawa garam, intrusi air garam, sungai atau danau (Mindari, 2009).

Menurut Mishra (2006) Azolla sangat sensitif apabila berada pada terhadap tekanan $\mathrm{NaCl} 4 \mathrm{dS} / \mathrm{m}$ atau kadar $5 \%$ air laut, sehingga untuk mendapatkan produktivitas Azolla yang maksimal pada media yang yang terpengaruh salin, perlu dilakukan penambahan air tawar dan penambahan bahan amelioran (bahan pembenah tanah) untuk mengurangi kadar salinitas.

Menurut Marwanto dkk. (2009) air mampu melarutkan molekul garam dan mengangkutnya sebagai aliran permukaan (run off) maupun pencucian (leaching) sehingga kadar garam, yang menyebabkan tanah menjadi salin dapat berkurang. Pada skala bentang tanah, salinitas tanah mampu berkurang akibat pasokan air hujan maupun dari air irigasi dalam volume dan intensitas yang cukup. Serta penggunaan bahan amelioran organik maupun anorganik.

Penambahan amelioran dapat meningkatkan ketersediaan hara $\mathrm{K}, \mathrm{Ca}, \mathrm{Mg}$, $\mathrm{N}$ dan $\mathrm{P}$, sehingga dapat mendukung pertumbuhan tanaman. Ameliorasi pada keadaan salin menggunakan pupuk kandang meningkatkan pertumbuhan akar, menurunkan daya hantar listrik dari 6,35 $\mathrm{dS} / \mathrm{m}$ menjadi 2,65 $\mathrm{dS} / \mathrm{m}$ dan SAR menurun dari 6,56 menjadi 11,60 (Shaaban dkk., 2013)

Menurut Wahyuningsih dkk. (2017) pemupukan $\mathrm{P}$ dan $\mathrm{K}$, penggunaan pupuk kandang, abu, dan dolomit dapat meningkatkan produksi kacang tanah dan kedelai pada tanah yang terpengaruh salinitas. Produksi kacang tanah dan kedelai mencapai $70 \%$ dibandingkan praktik lokal.

Menurut Gustian dan Totok (2005) penggunaan zeolit dalam menurunkan kadar garam dalam air dengan menggunakan larutan pengaktif ammonium nitrat dengan suhu kalsinasi $5000 \mathrm{C}$ dapat mengurangi kadar garam dalam air $65-84$.

Berdasarkan uraian tersebut dimuka, maka perlu dilakukan penelitian mengenai pengaruh variasi kadar salinitas media dan macam bahan amelioran terhadap pertumbuhan dan produksi Azolla microphylla Kaulf.

Penelitian dilakukan dengan tujuan sebagai berikut : Mengetahui kadar salinitas media yang optimum untuk pertumbuhan Azolla microphylla Kaulf, mengetahui bahan amelioran yang tepat untuk pertumbuhan Azolla microphylla Kaulf dan mengetahui interaksi antara kadar salinitas media dan macam bahan amelioran pada pertumbuhan Azolla microphylla Kaulf.

\section{BAHAN DAN METODE}

Percobaan dilaksanakan di Desa Toso, Kecamatan Bandar, Kabupaten Batang pada ketinggian 500 meter diatas permukaan laut ( $m$ dpl), mulai bulan Oktober 2018 sampai bulan November 2018. Rancangan yang digunakan adalah Rancangan Acak Kelompok (RAK) dengan perlakuan faktorial $4 \times 3$. Faktor pertama kadar salinitas media yang terdiri dari 4 taraf, yaitu $\mathrm{KO}=$ Air garam : Air tawar (0\%: 100\%), K1 = Air garam : Air tawar $(5 \%: 95 \%), \mathrm{K} 2$ = Air garam : Air tawar $(10 \%: 90 \%), \quad K 3=$ Air garam : Air tawar (15\% : $85 \%)$. Faktor kedua bahan amelioran terdiri dari 3 taraf yaitu A1 = Pupuk kandang sapi, $\mathrm{A} 2$ = Zeolit, $\mathrm{A} 3$ = Dolomit, dengan demikian terdapat 12 kombinasi, masingmasing kombinasi diulang tiga kali, sehingga seluruhnya ada $(4 \times 3) \times 3=36$ satuan percobaan.

Data yang diperoleh dianalisis dengan uji F. Jika antara faktor yang dicoba terdapat perbedaan nyata, maka analisis data dilanjutkan uji DMRT. Untuk kadar salinitas media dilanjutkan dengan uji regresi dan untuk macam amelioran dengan uji kontras orthogonal. Variabel yang diamati meliputi: (1) laju pertumbuhan relatif, (2) panjang batang, (3) panjang akar,(4) kemunculan jumlah akar, (5) pertambahan biomasa berat basah, (6) bobot kering, (7) waktu penggandaan, (8) kepadatan, (9) jumlah tanaman bertahan hidup, (10) kandungan $\mathrm{N}$ Azolla microphylla Kaulf segar, (11) kandungan $\mathrm{N}$ kompos Azolla microphylla Kaulf.

\section{HASIL DAN PEMBAHASAN Kadar Salinitas Media}

Hasil penelitian menunjukan bahwa kadar salinitas media berbeda sangat nyata terhadap semua variabel. Kadar salinitas 
media yang terbaik dicapai pada kadar salinitas media $0 \%$. Pada kadar salinitas media $0 \%$ Azolla tumbuh dengan baik, kadar salinitas media 5\% Azolla microphylla Kaulf masih mampu mentolerir keadaan salin, sedangkan pada kadar salinitas media 10\% dan $15 \%$ Azolla microphylla Kaulf mengalami cekaman salin. Hal ini disebabkan sel yang berada di larutan hipertonik mengakibatkan air berdifusi dari sitoplasma ke air garam, karena kadar larutan diluar sel lebih tinggi, sehingga air dalam sel akan keluar dan membran akan terlepas dari dinding sel. Hal ini sesuai pendapatnya Dachlan dkk. (2013) cekaman osmotik akibat pengaruh $\mathrm{NaCl}$ atau larutan yang bersifat hipertonik dimana

Tabel 1. Angka Rata-Rata dan Hasil Analisis Statistik Pada Pertumbuhan dan Produksi Azolla microphylla Kaulf

\begin{tabular}{|c|c|c|c|c|c|}
\hline Perlakuan & $\begin{array}{c}\text { LPR / } \\
\text { tanaman } \\
\text { (g/hari) }\end{array}$ & $\begin{array}{l}\text { Panjang } \\
\text { Batang / } \\
\text { tanaman } \\
(\mathrm{cm}) \\
\end{array}$ & $\begin{array}{l}\text { Panjang } \\
\text { Akar / } \\
\text { tanaman } \\
(\mathrm{cm}) \\
\end{array}$ & $\begin{array}{c}\text { Kemunculan } \\
\text { Jumlah Akar } \\
\text { / tanaman } \\
\text { (buah) }\end{array}$ & $\begin{array}{c}\text { Pertambahan } \\
\text { Biomasa } \\
\text { Berat Basah / } \\
\text { tanaman }(\mathrm{g})\end{array}$ \\
\hline \multicolumn{6}{|l|}{ Kadar Salinitas Media } \\
\hline $\begin{array}{l}\text { K0 = Air garam : Air tawar } \\
(0 \%: 100 \%)\end{array}$ & $0,0426 c$ & $1,5333 c$ & $3,4 d$ & $48,9556 b$ & $0,0458 c$ \\
\hline $\begin{array}{l}\text { K1 = Air garam : Air tawar } \\
(5 \%: 95 \%)\end{array}$ & $0,0384 c$ & $1,3778 \mathrm{bc}$ & $2,5667 c$ & $37,3333 a b$ & $0,0393 b c$ \\
\hline $\begin{array}{l}\text { K2 = Air garam : Air tawar } \\
(10 \%: 90 \%)\end{array}$ & $0,0259 b$ & $1,2556 a b$ & $1,4222 b$ & $33,5556 a$ & $0,025 a b$ \\
\hline $\begin{array}{l}\text { K3 = Air garam : Air tawar } \\
(15 \%: 85 \%)\end{array}$ & $0,0172 a$ & $1,1333 a$ & $0,8889 a$ & $28,5111 a$ & $0,0177 a$ \\
\hline \multicolumn{6}{|l|}{ Macam Bahan Amelioran } \\
\hline $\begin{array}{l}\text { A1 = Pupuk Kandang } \\
\text { Sapi }\end{array}$ & $0,04 b$ & $1,5833 b$ & $1,8 a$ & $49,75 b$ & $0,0441 b$ \\
\hline $\begin{array}{l}\mathrm{A} 2=\text { Zeolit } \\
\mathrm{A} 3=\text { Dolomit }\end{array}$ & $\begin{array}{l}0,0253 a \\
0,0277 a\end{array}$ & $\begin{array}{l}1,1583 a \\
1,2333 a\end{array}$ & $\begin{array}{l}2,3917 c \\
2,0167 b\end{array}$ & $\begin{array}{c}32,4167 a \\
29,1 a\end{array}$ & $\begin{array}{l}0,0284 a \\
0,0234 a\end{array}$ \\
\hline
\end{tabular}

larutan tersebut memiliki kepekatan atau kandungan zat yang terlarut yang lebih tinggi dari pada air maka air dari dalam sel akan berpindah ke luar sel untuk menyeimbangkan kondisi pada larutan tersebut. Hal ini menyebabkan sel tumbuhan mengalami plasmolisis dimana sel tumbuhan kehilangan air sehingga protoplasma lepas dari dinding sel. Pada kondisi kekurangan air pembesaran sel akan menurun akibat dari rendahnya turgiditas sel. Hilangnya turgiditas sel dapat menghentikan pertumbuhan sel (penggandaan dan pembesaran sel) sehingga menghambat pertumbuhan tanaman.

\section{Macam Bahan Amelioran}

Hasil penelitian menunjukan bahwa bahan amelioran berbeda nyata terhadap semua variabel. Bahan amelioran pupuk kandang sapi menunjukkan nilai terbaik pada semua variabel kecuali panjang akar. Nilai panjang akar tertinggi dicapai pada bahan amelioran zeolit.

Pupuk kandang sapi memiliki nutrisi yang lengkap baik makro maupun mikro, sehingga mampu meningkatkan pertumbuhan Azolla. Menurut Riyani dkk. (2013) pupuk organik mampu menyediakan unsur hara, sehingga tanaman dapat memanfaatkan unsur hara yang terdapat pada pupuk organik. Ketersediaan unsur hara $\mathrm{N}$ dan $\mathrm{P}$ meningkatkan perkembangan akar, sehingga membantu dalam penyerapan unsur hara makro $\mathrm{K}$ dan $\mathrm{Ca}$, dan penyerapan unsur hara mikro $\mathrm{Mn}$, Fe, Cu dan Zn. Unsur hara $\mathrm{N}$ yang tersedia dalam jumlah yang cukup yang merupakan unsur hara makro penting dalam proses fotosintesis serta unsur $\mathrm{N}$ diperlukan dalam pembentukan bagianbagian vegetatif tanaman, sehingga pertumbuhan tanaman dapat berjalan lancar,

Pada bahan amelioran zeolit menunjukkan nilai terbaik pada panjang akar. Diduga pada zeolit memiliki pori-pori yang terisi ion-ion yang dapat titukarkan. Hal ini 
sesuai pendapatnya Nurmansyah (2016) bahwa zeolit mempunyai pori-pori yang permukaannya bermuatan negatif sehingga dapat mencegah pencucian unsur hara $\mathrm{NH} 4+$ dan kation $\mathrm{K}+$ dari daerah perakaran.
Pori-pori zeolit terisi ion $\mathrm{K}, \mathrm{Na}, \mathrm{Ca}, \mathrm{Mg}$, dan molekul $\mathrm{H} 2 \mathrm{O}$ sehingga memungkinkan terjadinya pertukaran ion dan pelepasan air secara bolak-balik, sehingga mampu meningkatkan pemanjangan akar.

Tabel 2. Angka Rata-Rata dan Hasil Analisis Statistik Pada Pertumbuhan dan Produksi Azolla microphylla Kaulf

\begin{tabular}{|c|c|c|c|c|c|}
\hline Perlakuan & $\begin{array}{c}\text { Bobot } \\
\text { Kering / } \\
\text { tanaman } \\
\text { (g) }\end{array}$ & $\begin{array}{c}\text { Waktu } \\
\text { Penggand } \\
\text { aan / } \\
\text { tanaman } \\
\text { (hari) }\end{array}$ & $\begin{array}{c}\text { Kepadatan } \\
\text { / bak plstik } \\
\text { (ind/cm2) }\end{array}$ & $\begin{array}{l}\text { Jumlah } \\
\text { tanaman } \\
\text { bertahan } \\
\text { hidup / bak } \\
\text { plastik } \\
\text { (ind) }\end{array}$ & $\begin{array}{c}\text { Kandungan } \\
\text { N Azolla } \\
\text { segar / } \\
\text { sampel } \\
(\%) \\
\end{array}$ \\
\hline \multicolumn{6}{|l|}{ Kadar Salinitas Media } \\
\hline $\begin{array}{l}\text { K0 = Air garam : Air tawar } \\
(0 \%: 100 \%)\end{array}$ & $0,0101 \mathrm{c}$ & $11,5602 \mathrm{a}$ & $2760 d$ & $483 d$ & $1,6446 b$ \\
\hline $\begin{array}{l}\text { K1 = Air garam : Air tawar } \\
(5 \%: 95 \%)\end{array}$ & $0,0093 b c$ & $13,7585 b$ & $2049,52 c$ & $358,67 c$ & $1,6397 b$ \\
\hline $\begin{array}{l}\text { K2 = Air garam : Air tawar } \\
(10 \%: 90 \%)\end{array}$ & $0,0084 a b$ & $18,6894 \mathrm{c}$ & $1133,97 b$ & $198,44 b$ & $1,2472 \mathrm{ab}$ \\
\hline $\begin{array}{l}\text { K3 = Air garam : Air tawar } \\
(15 \%: 85 \%)\end{array}$ & $0,0075 a$ & $20,5915 d$ & $851,43 a$ & $149 a$ & 1,0793a \\
\hline \multicolumn{6}{|l|}{ Macam Bahan Amelioran } \\
\hline A1 = Pupuk Kandang Sapi & $0,0099 b$ & $8,6717 a$ & $3243,33 b$ & $567,58 b$ & $1,7179 b$ \\
\hline A2 = Zeolit & $0,0085 a$ & $21,0972 c$ & $891,43 a$ & $156 a$ & $1,2323 a$ \\
\hline A3 $=$ Dolomit & $0,008 a$ & $18,6808 \mathrm{~b}$ & $961,43 a$ & $168,25 a$ & $1,256 \mathrm{a}$ \\
\hline
\end{tabular}

Interaksi antara Kadar Salinitas Media dan Macam Bahan Amelioran

Hasil analisis statistik menunjukkan bahwa terdapat interaksi antara kadar salinitas media dengan macam bahan amelioran terhadap variabel pengamatan. Kombinasi perlakuan kadar salinitas media $0 \%$ dan $5 \%$ dengan macam bahan amelioran

Tabel 3. Angka rata-rata Interaksi Penelitian Pengaruh Kadar Salinitas Media dan Macam Bahan Amelioran

\begin{tabular}{lcccccc}
\hline Perlakuan & $\begin{array}{c}\text { LPR/ } \\
\text { tanaman } \\
(\mathrm{g} / \mathrm{hari})\end{array}$ & $\begin{array}{c}\text { Panjang } \\
\text { batang / } \\
\text { tanaman } \\
(\mathrm{cm})\end{array}$ & $\begin{array}{c}\text { Panjang } \\
\text { Akar / } \\
\text { tanaman } \\
(\mathrm{cm})\end{array}$ & $\begin{array}{c}\text { Kemunculan } \\
\text { Jumlah Akar } \\
\text { /tanaman } \\
\text { (buah) }\end{array}$ & $\begin{array}{c}\text { Pertambahan } \\
\text { Biomasa } \\
\text { Berat Basah / } \\
\text { tanaman }(\mathrm{g})\end{array}$ & $\begin{array}{c}\text { Bobot } \\
\text { kering/ } \\
\text { tanaman }(\mathrm{g})\end{array}$ \\
\hline $\mathrm{K}_{0} \mathrm{~A}_{1}$ & $0,0492 \mathrm{~d}$ & $2,0333 \mathrm{c}$ & $2,5667 \mathrm{e}$ & $57,1333 \mathrm{e}$ & $0,056 \mathrm{c}$ & $0,0111 \mathrm{~d}$ \\
$\mathrm{~K}_{0} \mathrm{~A}_{2}$ & $0,0394 \mathrm{~cd}$ & $1,2333 \mathrm{a}$ & $3,9 \mathrm{~g}$ & $47,3333 \mathrm{~cd}$ & $0,0444 \mathrm{c}$ & $0,01 \mathrm{~cd}$ \\
$\mathrm{~K}_{0} \mathrm{~A}_{3}$ & $0,0390 \mathrm{~cd}$ & $1,3333 \mathrm{ab}$ & $3,7333 \mathrm{~g}$ & $42,4 \mathrm{c}$ & $0,037 \mathrm{bc}$ & $0,0092 \mathrm{bcd}$ \\
$\mathrm{K}_{1} \mathrm{~A}_{1}$ & $0,0397 \mathrm{~cd}$ & $1,6333 \mathrm{~b}$ & $2,1667 \mathrm{~d}$ & $53,3333 \mathrm{de}$ & $0,0383 \mathrm{bc}$ & $0,0092 \mathrm{bcd}$ \\
$\mathrm{K}_{1} \mathrm{~A}_{2}$ & $0,0373 \mathrm{~cd}$ & $1,2667 \mathrm{a}$ & $2,9333 \mathrm{f}$ & $32,2 \mathrm{ab}$ & $0,0473 \mathrm{c}$ & $0,0099 \mathrm{~cd}$ \\
$\mathrm{~K}_{1} \mathrm{~A}_{3}$ & $0,0381 \mathrm{~cd}$ & $1,2333 \mathrm{a}$ & $2,6 \mathrm{e}$ & $26,4667 \mathrm{a}$ & $0,0323 \mathrm{abc}$ & $0,0086 \mathrm{abc}$ \\
$\mathrm{K}_{2} \mathrm{~A}_{1}$ & $0,0367 \mathrm{~cd}$ & $1,4 \mathrm{ab}$ & $1,5 \mathrm{c}$ & $48,8667 \mathrm{cde}$ & $0,0471 \mathrm{c}$ & $0,0106 \mathrm{~cd}$ \\
$\mathrm{~K}_{2} \mathrm{~A}_{2}$ & $0,0155 \mathrm{ab}$ & $1,1333 \mathrm{a}$ & $1,5667 \mathrm{c}$ & $27,2 \mathrm{a}$ & $0,0128 \mathrm{ab}$ & $0,0074 \mathrm{ab}$ \\
$\mathrm{K}_{2} \mathrm{~A}_{3}$ & $0,0253 \mathrm{bc}$ & $1,2333 \mathrm{a}$ & $1,2 \mathrm{~b}$ & $24,6 \mathrm{a}$ & $0,015 \mathrm{ab}$ & $0,0073 \mathrm{ab}$ \\
$\mathrm{K}_{3} \mathrm{~A}_{1}$ & $0,0343 \mathrm{~cd}$ & $1,2667 \mathrm{ab}$ & $0,9667 \mathrm{~b}$ & $39,6667 \mathrm{bc}$ & $0,035 \mathrm{abc}$ & $0,0086 \mathrm{abc}$ \\
$\mathrm{K}_{3} \mathrm{~A}_{2}$ & $0,0087 \mathrm{a}$ & $1,0333 \mathrm{a}$ & $1,1667 \mathrm{~b}$ & $22,9333 \mathrm{a}$ & $0,009 \mathrm{a}$ & $0,0069 \mathrm{a}$ \\
$\mathrm{K}_{3} \mathrm{~A}_{3}$ & $0,0084 \mathrm{a}$ & $1,1333 \mathrm{a}$ & $0,5333 \mathrm{a}$ & $22,9333 \mathrm{a}$ & $0,0092 \mathrm{a}$ & $0,007 \mathrm{a}$ \\
\hline
\end{tabular}

Keterangan : Keterangan : Angka yang diikuti huruf yang sama pada kolom dan baris menunjukkan tidak berbeda nyata menurut uji BNT taraf 5\% 
pupuk kandang sapi menunjukkan nilai tertinggi semua variabel kecuali panjang akar, karena pada kadar salinitas media $0 \%$ dan $5 \%$ unsur hara hara makro (N,P,K dan $\mathrm{Ca})$ dan unsur hara mikro yaitu $(\mathrm{Mn}, \mathrm{Fe}, \mathrm{Cu}$ dan $\mathrm{Zn}$ ) dapat terserap dengan baik oleh
Azolla, sehingga pada kadar salinitas media $0 \%$ dan $5 \%$ dan bahan amelioran pupuk kandang sapi mampu meningkatkan pertumbuhan vegetatif dan kemampuan bertahan hidup Azolla microphylla pada media salin.

Tabel 4. Angka rata-rata Interaksi Penelitian Pengaruh Kadar Salinitas Media dan Macam Bahan Amelioran

\begin{tabular}{|c|c|c|c|c|c|c|}
\hline Perlakuan & $\begin{array}{c}\text { Waktu } \\
\text { Penggandaan } \\
\text { / tanaman } \\
\text { (hari) }\end{array}$ & $\begin{array}{c}\text { Kepadatan } \\
\text { / bak } \\
\text { plastik } \\
\text { (ind/cm2) }\end{array}$ & $\begin{array}{c}\text { Jumlah } \\
\text { tanaman } \\
\text { bertahan } \\
\text { hidup / bak } \\
\text { plastik (ind) }\end{array}$ & $\begin{array}{l}\text { Kandungan } \\
\text { N Azolla } \\
\text { segar / } \\
\text { sampel (\%) }\end{array}$ & $\begin{array}{c}\text { Kandungan } \\
\text { N kompos } \\
\text { Azolla / } \\
\text { sampel (\%) }\end{array}$ & $\begin{array}{c}\text { Waktu } \\
\text { Pengganda } \\
\text { an / } \\
\text { tanaman } \\
\text { (hari) }\end{array}$ \\
\hline $\mathrm{K}_{0} \mathrm{~A}_{1}$ & $5,8358 a$ & $6293,33 f$ & $1101,33 f$ & $2,3651 c$ & $2,369 e$ & $5,8358 a$ \\
\hline $\mathrm{K}_{0} \mathrm{~A}_{2}$ & $14,6599 b$ & $946,67 \mathrm{bc}$ & $165,67 \mathrm{bc}$ & $1,2044 a$ & $1,8564 \mathrm{~cd}$ & $14,6599 b$ \\
\hline $\mathrm{K}_{0} \mathrm{~A}_{3}$ & $14,1847 b$ & $1040 c$ & $182 \mathrm{c}$ & $1,3643 a$ & $2,0516 \mathrm{cde}$ & $14,1847 b$ \\
\hline$K_{1} A_{1}$ & $6,6952 a$ & $4146,67 e$ & $725,67 e$ & $2,1455 b c$ & 2,2299de & $6,6952 a$ \\
\hline$K_{1} A_{2}$ & $19,2599 c$ & $948,57 \mathrm{bc}$ & $166 b c$ & $1,4492 a b$ & $1,7452 b c$ & $19,2599 c$ \\
\hline$K_{1} A_{3}$ & $15,3205 b$ & $1053,33 c$ & $184,33 c$ & $1,3747 a$ & $1,8018 c$ & $15,3205 b$ \\
\hline$K_{2} A_{1}$ & $8,8075 a$ & $1560 d$ & $273 d$ & $1,2901 a$ & 1,979 cde & $8,8075 a$ \\
\hline$K_{2} A_{2}$ & $24,9668 d$ & $916,19 a b c$ & $160,33 \mathrm{abc}$ & $1,2468 a$ & $1,6597 \mathrm{bc}$ & $24,9668 d$ \\
\hline$K_{2} A_{3}$ & $22,2938 \mathrm{~cd}$ & $925,71 b c$ & $162 \mathrm{bc}$ & $1,2048 a$ & $1,8728 \mathrm{~cd}$ & $22,2938 \mathrm{~cd}$ \\
\hline$K_{3} A_{1}$ & $13,3482 b$ & $973,33 b c$ & $170,33 \mathrm{bc}$ & $1,0759 a$ & $1,9864 \mathrm{cde}$ & $13,3482 b$ \\
\hline $\mathrm{K}_{3} \mathrm{~A}_{2}$ & $25,5022 d$ & $754,29 a$ & $132 a$ & $1,029 a$ & $1,0485 a$ & $25,5022 d$ \\
\hline $\mathrm{K}_{3} \mathrm{~A}_{3}$ & $22,9241 d$ & $826,67 a b$ & $144,67 a b$ & $1,1332 \mathrm{a}$ & 1,389ab & $22,9241 d$ \\
\hline
\end{tabular}

Hal ini sesuai pendapatnya Muharam (2017) bahwa bahan orgnaik dari pupuk kandang dapat memperbaiki sifat biologi pada lahan salin. Bahan organik yang sudah terdekomposisi dengan baik mampu menyediakan hara yang dibutuhkan tanaman terutama nitrogen. Bahan organik yang terdekomposisi dengan baik akan mengalami proses mineralisasi $\mathrm{N}$ organik.

\section{Simpulan}

Berdasarkan hasil penelitian dan pembahasan dapat ditarik beberapa simpulan sebagai berikut :

1. Kadar salinitas media berbeda sangat nyata terhadap variabel pengamatan. Kadar salinitas media 5\% merupakan kadar yang masih toleran terhadap pertumbuhan Azolla microphylla Kaulf pada kondisi salin.

2. Bahan amelioran pupuk kandang sapi merupakan bahan amelioran terbaik pada pertumbuhan Azolla microphylla Kaulf. Pengaruh bahan amelioran berbeda sangat nyata terhadap semua variabel pengamatan.

3. Terjadi interaksi antara kadar salinitas media dan macam bahan amelioran pada pertumbuhan tanaman Azolla microphylla Kaulf terhadap semua variabel yang diamati. Kombinasi terbaik dicapai pada kadar salinitas media 5\% dengan bahan amelioran pupuk kandang sapi pada kondisi salin, dan Azolla microphylla Kaulf dapat tumbuh sampai kadar salinitas media $15 \%$.

\section{DAFTAR PUSTAKA}

Dachlan, A., N. Kasim, dan Kurnia. 2013. Uji Ketahanan Salinitas Beberapa Varietas Jagung (Zea mays L.) Dengan Menggunakan Agen Seleksi $\mathrm{NaCl}$. Jurnal Biogenesis. ISSN 2302-1616 Vol 1, No. 1.,Fakultas Pertanian,Universitas Hasanuddin. Hal 9-17. 
journal.uinalauddin.ac.id/index.php/ biogenesis/article/view/442/0. Diakses pada 10 September 2018.

Gustian, I. dan Totok E. S. 2005. Studi penurunan salinitas air dengan menggunakan Zeolit alam yang berasal dari bengkulu. Jurnal Gradien Vol.1 :38-42.

https://ejournal.unib.ac.id/index.php /gradien/article/viewFile/191/165. Diakses pada 10 Agustus 2018.

Irawan, Diah Setyorini, dan Sri Rochayati. 2017. Proyeksi Kebutuhan Pupuk Sektor Pertanian melalui Pendekatan Sistem Dinamis. Balittanah Bogor. http://balittanah.litbang.pertanian.go .id/ind/dokumentasi/lainnya/09\%20\%20Irawan\%20et\%20al\%20\%20Pr oyeksi\%20Kebutuhan\%20Pupuk\% 20Sektor\%20Pertanian\%20Melalui \%20Pendekatan\%20Sistem\%20Din amis.pdf. Diakses pada 5 September 2018.

Mamang, K. I., Umarie, dan Hudaini. 2017. Application of Various Kinds of Azolla Fertilizer (Azolla microphylla) and Interval Time Applications to Growth and Soybean Production (Glycine Max (L) Merill). Jurnal Agritrop. Fakultas Pertanian Universitas Muhammadiyah Jember. Volume 15 http://jurnal.unmuhjember.ac.id/ index.php/AGRITROP. Diakses pada 17 September 2018.

Marwanto, S., A. Rachman, D. Erfandi, dan I G.M. Subiksa. 2009. Tingkat Salinitas Tanah pada Tanah Sawah Intensif di Kabupaten Indramayu, Jawa Barat. Balai Penelitian Tanah, Bogor.balittanah.litbang.pertanian.g o.id/ind/index.php/publikasimainmenu-78/.../329-salin. Diakses pasa 20 Agustus 2018.

Mindari, W. 2009. Cekaman garam dan Dampaknya pada kesuburan tanah dan tanaman. UPN Veteran Jawa Timur, Surabaya.
Mishra, A. K.. 2006. Protection Against Salt Toxicity In Azolla PinnataAnabaena Azollae Symbiotic Association By Using Combined-N Sources. Department of Botany, Banaras Hindu University. Acta Biologica Hungarica 57 (3)

Muharam. 2017. Efektivitas Penggunaan Pupuk Kandang dan Pupuk Organik Cair Dalam Meningkatkan Pertumbuhan dan Hasil Tanaman Kedelai (Glycine Max L.) Varietas Anjasmoro di Tanah Salin. Jurnal Agrotek Indonesia 2 (1) : $44-53$

Nurmansyah. 2016. Pengaruh Jenis Dan Dosis Amelioran Terhadap Pertumbuhan Dan Hasil Padi (Oryza Sativa L.) Pada Penanaman Kedua. Skripsi (on-line). Sekolah Tinggi Ilmu Pertanian Dharma Wacana Metro Lampung. http://eprints.stiperdharmawacana.a c.id/227/1/NURMANSYAH_121100 59.PDF. Diakses pada 21 September 2018.

Riyani, R., Radian dan S. Budi. 2013. Pengaruh berbagai Pupuk Organik terhadap Pertumbuhan dan Hasil Padi di Lahan Pasang Surut. Jurnal. Fakultas Pertanian Universitas Tanjungpura Pontianak. https://media.neliti.com/media/publi cations/190633-ID-pengaruhberbagai-pupuk-organikterhadap.pdf. Diakses pada 22 Agustus 2018.

Shaaban, M., M. Abid, R.A.I. Abou-Shanab. 2013. Amelioration of salt affected soils in rice paddy systemby application of organic and inorganic amendments. Plant Soil Environ. 59(5): 227-233. https://experts.umn.edu/en/publicati ons/amelioration-of-salt-affectedsoils-in-rice-paddy-system-by-appli. Diakses pada 20 September 2018. 
Surdina, E., Sayyid Afdhal El-Rahimi dan Iwan Hasri3. 2016. Pertumbuhan Azolla microphylla Dengan Kombinasi Pupuk Kotoran Ternak. Jurnal IImiah Mahasiswa Kegaraman dan Perikanan Unsyiah, Volume 1, Nomor 3
Wahyuningsih, S., Afandi Kristiono, dan Abdullah Taufiq. 2017. Pengaruh Jenis Amelioran terhadap Pertumbuhan dan Hasil Kacang Hijau di Tanah Salin. Jurnal. Vol. 15 No.

2. https://media.neliti.com/media/publi cations/225864-pengaruhameliorasi-tanah-salin-terhadapc12cfd35.pdf. diakses pada 29 Agustus 2018. 